\title{
IMPROVEMENT OF FATIGUE LIFE OF A HOLED SPECIMEN OF ALUMINUM-ALLOY 2024-T3 BY INDENTATION AND HOLE EXPANSION
}

\author{
MD. SHAFIUL FERDOUS \\ Graduate School of Engineering and Science, University of the Ryukyus \\ 1 Senbaru, Nishihara, Okinawa 903-0213, Japan \\ munazeer_218@yahoo.com \\ CHOBIN MAKABE and TATSUJIRO MIYAZAKI \\ Mechanical Systems Engineering Department, University of the Ryukyus, \\ 1 Senbaru, Nishihara, Okinawa 903-0213, Japan \\ makabe@tec.u-ryukyu.ac.jp and t-miya@tec.u-ryukyu.ac.jp \\ NOBUSUKE HATTORI \\ Department of Mechanical Systems Engineering, Saga University, \\ Honsho 1, Saga-city, Saga 840-8502, Japan \\ hattori@me.saga-u.ac.jp
}

\begin{abstract}
A method of improving the fatigue life and crack growth behavior of a center holed specimen was investigated. Local plastic deformation was applied around the hole by indentation to achieve the purpose. A series of fatigue tests was conducted on aluminum-alloy 2024-T3. Push-pull tests were performed under a stress ratio of $R=-1$ and a frequency of $10 \mathrm{~Hz}$. The observations of the crack initiation and growth were performed with a microscope, and hardness around the hole was measured by Vickers hardness testing machine. In the present study, the longest fatigue life was observed in the case of an indentation specimen with the highest load. The indentation was performed on both sides of the hole edges. The crack growth rate was decreased by indentation or expansion of the material around the hole. From the experimental results, it is found that the fatigue life and crack growth behavior of a holed or notched specimen can be improved by a simple technical method that is related to the local plastic working.
\end{abstract}

Keywords: Improvement of fatigue life; Holed specimen; Indentation; Plastic deformation.

\section{Introduction}

Many structural components have sources of stress concentration such as notches, key slots and so on. It is a common issue for fatigue cracks emanating from notches during overloading operations to be a concern for designer. Several mechanical processes for enhancement of the fatigue life are performed [1-4]. For example, a method commonly promoted in the aeronautical industry is to drill a stop hole and apply cold working to notches or holes $[1,2]$. Reducing stress concentration at the crack tip and the 
development of compressive residual stress on the crack growth path are causes for the improvement of fatigue life. The main objective of the present study is to contribute to the further understanding of the effect of local plastic deformation in notched parts on the fatigue life of structural engineering components.

During the last several years, extensive research has been carried out to enhance the fatigue life of aluminum alloys by expanding holes or notches and the effect of the compressive residual stresses on crack growth behavior has been discussed $[3,4]$. In the present study, local plastic deformation was applied around the hole or notch by the indentation process and material around the hole was expanded. The relationship among the fatigue life, local plastic deformation and hardness distribution was investigated by basic experiment.

\section{Material and Testing Procedure}

Material used was rolled plate of 2024-T3 aluminum-alloy with $3 \mathrm{~mm}$ thickness. The chemical composition and mechanical properties of this material are shown in Table 1 and Table 2, respectively.

Table 1 Chemical composition (mass \%)

\begin{tabular}{llllllllllll}
\hline $\mathrm{Si}$ & $\mathrm{Fe}$ & $\mathrm{Cu}$ & $\mathrm{Mn}$ & $\mathrm{Mg}$ & $\mathrm{Cr}$ & $\mathrm{Zn}$ & $\mathrm{Ti}$ & $\mathrm{Zn}+\mathrm{Ti}$ & Others & $\mathrm{Al}$ & \\
\hline 0.07 & 0.18 & 4.48 & 0.55 & 1.51 & 0.03 & 0.08 & 0.02 & 0.03 & 0.01 & Bal. \\
\hline
\end{tabular}

Table 2 Mechanical properties (MPa, \%)



(a) Specimen geometry ( $\mathrm{mm})$.

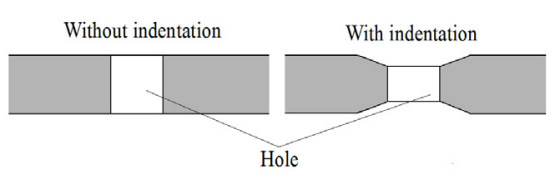

(b) Cross section of the holed site.

Fig.1. Shape of the specimen used in fatigue tests.

Fig. 1 shows the geometry of the specimen in which a hole of $5 \mathrm{~mm}$ diameter was drilled in the center of the testing section. Indentation was done on both sides of the hole edges in some specimens by using a steel ball of $10 \mathrm{~mm}$ diameter. The initial diameter of the hole was reduced due to the indentation process. The material around the hole expanded towards the hole center and a dimple was generated around the hole. While the dimple was being made, the diameter of the hole became smaller depending on the 
indentation load. The loading axis of the specimen was in the longitudinal direction (LD) or transverse direction (RD) of the rolled plate.

A servo-hydraulic testing machine was used for the fatigue tests. The experiments were performed at room temperature. All specimens were subjected to cyclic loading with sinusoidal wave-form and frequency of $10 \mathrm{~Hz}$. The applied load was push-pull loading with a stress ratio (Minimum cyclic stress $S_{\min } /$ maximum cyclic stress $S_{\max }$ ) of $R=-1$. Crack growth behavior was observed by optical microscope. The microscope was connected to an image display system device to make it easy to monitor and to measure the crack length. All specimen surfaces were given a mirror like polish with emery paper and metal abrasives before and after indentation process.

\section{Results and Discussion}

\subsection{Improvement of fatigue life of a holed specimen by indentation}

The stress interferences between applied stress and residual stress related to indentation load or the dimple diameter affected fatigue life. Fig. 2 shows the fatigue life of holed specimens with and without indentation. Where, $S_{a}$ and $N_{\mathrm{f}}$ are stress amplitude and number of cycles to failure, respectively. The fatigue life of a specimen cut in LD was shorter than that of a specimen cut in RD where the indentation was applied. This is an inverse tendency compared to the testing of specimens without indentation. It is also found that fatigue life increased after the indentation, and it became even longer when 14.7MPa of indentation load $F_{\mathrm{i}}$ was applied to the specimen cut in RD. In the later section, the reason for this will be discussed from the view point of residual stress.

In some specimens, the effect of strain ageing on fatigue life was examined. After the indentation was applied with $F_{\mathrm{i}}=9.8 \mathrm{MPa}$ or $14.7 \mathrm{MPa}$, the specimens cut in LD were left one month before testing. Then fatigue tests were done with $S_{\alpha}=100 \mathrm{MPa}$. It was found that the fatigue life of the specimen with aging $(\boldsymbol{\square}, \bullet)$ was getting longer than that of the specimen without aging $(\boldsymbol{\Lambda}, \boldsymbol{\nabla})$. So, the fatigue life of the present type of holed specimen would be changed during a long time operation. This behavior will be examined more in the future to discuss important factors of material properties for machine maintenance.

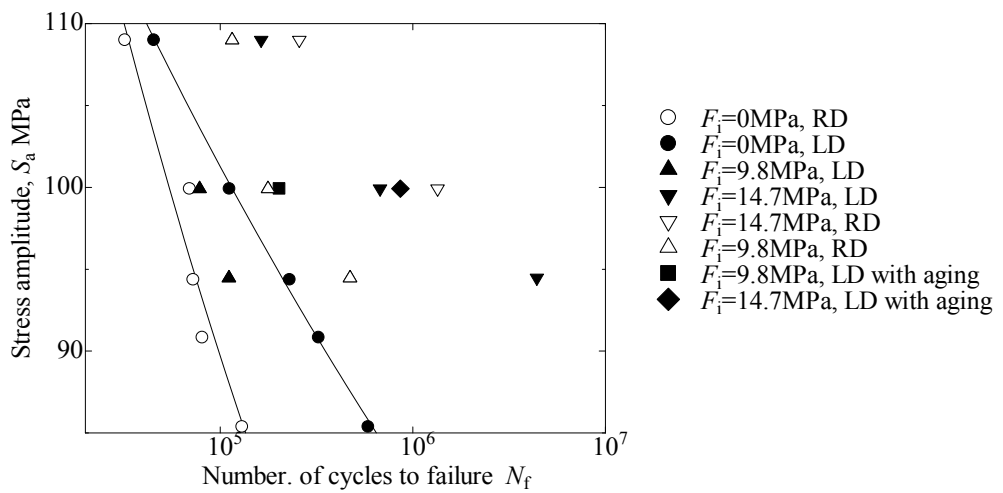

Fig. 2. $S / N$ curves of the holed specimens with and without indentation. 


\subsection{Crack growth behavior before and after the indentation}



(a)



(b)

Fig. 3. Comparison of crack growth behavior where $S_{a}=100 \mathrm{MPa}$ : (a) $N$ vs. $2 a$, (b) $N / N_{\mathrm{f}}$ vs. $2 a$.

The total crack length $2 a$, which includes the hole or dimple diameter, on the specimen surface as a function of the number of stress cycles $N$ is shown in Fig. 3. The number of cycles $N_{\mathrm{i}}$ where the crack initiation was observed at hole edge or dimple edge on the surface, and the number of cycles to failure $N_{\mathrm{f}}$ were affected by the indentation and ageing. The initial crack length $2 a_{o}$ coincides with the diameter of the hole or dimple.

The results in cases of $S_{a}=100 \mathrm{MPa}$ are shown in Fig.3, and similar results were obtained in the cases of other levels of $S_{a}$. From Fig. 3(a), it is found that the cycles $N_{\mathrm{i}}$, in which the crack initiation was observed on the specimen surface at hole or dimple edges, were made longer by indentation. Now, the first plot of each experimental data in Fig. 3 is the starting point for measurement of crack growth size. Also, it is found that crack growth life $\left(N-N_{\mathrm{i}}\right)$ on the specimen surface is improved by indentation. The direction in which the specimen was cut affect the fatigue life, thus the fatigue life of the specimen cut in RD was longer than that of the specimens cut in LD in the same loading conditions. This result is very interesting and the reason for this will be discussed in the next section.

In Fig. 3(b), the crack length at the crack growth stage is summarized by relative numbers of cycles $N / N_{\mathrm{f}}$. The crack growth behavior on the surface is related to the improvement of the fatigue life of holed specimens by indentation. It is found that the tendency of $2 a-N / N_{\mathrm{f}}$ curves for the specimen varies depending on the indentation levels and application of ageing. Thus, a master curve of the crack growth cannot be drawn in the present experiment. The crack growth behavior on the specimen surface is summarized in Fig. 3. However, the results of Fig. 2 are also related to the crack growth in the internal section. Before observing the crack on the surface, the crack initiated from the bottom of the hole in internal section, small cracks were initiated and grew. If a crack was initiated at the first stage of fatigue life, we can roughly approximate the crack growth curve. Thus, in such a case, the average crack growth curve was roughly approximated by a straight line from the point of $(2 a, N)=(5,0)$ to the first measurement data of $2 a-N$ relation. Anyway, before the number of cycles $N_{\mathrm{i}}$, a small crack grew inside of the specimen, but it did not grow rapidly. 


\subsection{Hardness distribution related to the residual stress and fracture surface}

To discuss the causes of improvement of fatigue life by indentation, Vickers hardness distribution was examined as shown in Figs. 4 and 5.



(a)

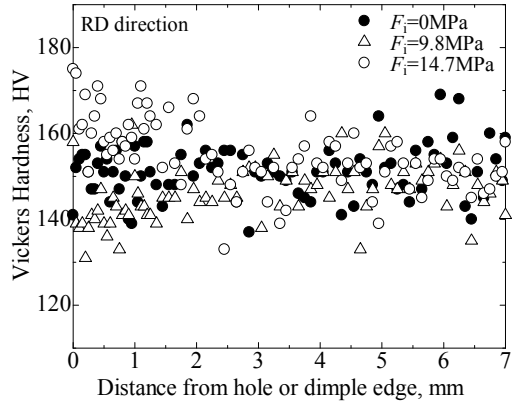

(b)

Fig.4 Vickers hardness distribution in the specimen surface before ageing: (a) Cut in LD, (b) Cut in RD.

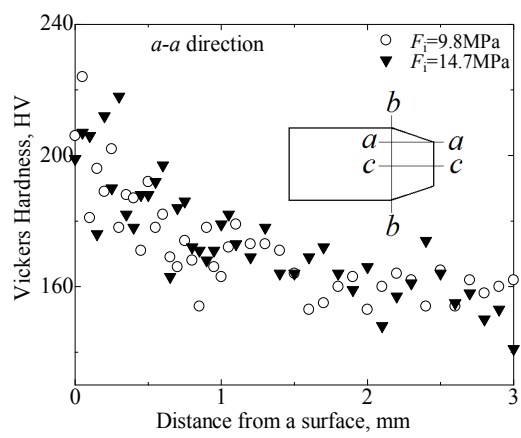

(a)

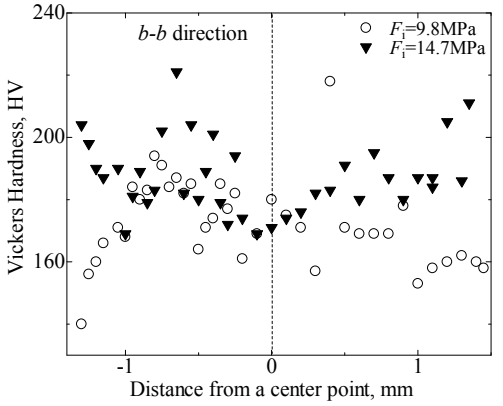

(b)

Fig. 5. Vickers hardness distribution after ageing (At the cross section of indented specimen cut in LD): (a) $a$ - $a$ direction, (b) $b-b$ direction.

Fig. 4 shows the measurement results of hardness on the specimen surface where the measurements were done just after indentation. The hardness of an indentation load of $F_{\mathrm{i}}=9.8 \mathrm{MPa}$ was almost the same as that of no indentation $\left(F_{\mathrm{i}}=0 \mathrm{MPa}\right)$. But, a higher hardness level than that was measured in the vicinity of the dimple edge in the case of $F_{\mathrm{i}}$ $=14.7 \mathrm{MPa}$. The hardness distribution was scattered in the case of specimens cut in RD, but the average hardness in the case of $F_{\mathrm{i}}=14.7 \mathrm{MPa}$ of the specimens cut in RD was almost the same as that of the specimens cut in LD. Therefore, the resistance to crack growth became higher in the case where the specimen was cut in RD than in the case of a specimen cut in LD due to initiation of compressive residual stress around the hole. The hardness distributions and residual stress conditions would be related to the $S-N$ relations and the crack growth curves. 
It is found from Fig. 5 that the hole edges were hardened after strain ageing. The higher value of HV was closer to 230. From a comparison of the data at the surface between Fig. 4 (b) and Fig. 5 (b), it is confirmed that the specimen hardness was being raised by strain aging. Also, the hardness was distributed from the surface layer to the internal section. At the dimple edge, higher hardness was obtained after strain ageing. The internal section in the vicinity of the hole edge was hardened by strain ageing in $F_{\mathrm{i}}$ $=9.8 \mathrm{MPa}$ and $14.7 \mathrm{MPa}$. On the surface layer, the hardening was observed in the case of $F_{\mathrm{i}}=14.7 \mathrm{MPa}$, only. This hardness distribution would make residual stress. Where a higher indentation load was applied, a longer fatigue life was obtained by those effects.

Fig. 6 shows examples of the fracture surfaces of specimens with indentation. The left sides of the pictures show the bottom of the hole. At the inner section of hole bottom, beach marks are observed. Therefore, the crack initiated at the inner section of the bottom of the hole and grew stably. Also, it is found that a small area of shear lips was created. The patterns of the fracture surface show that the crack grew with opening mode and shear mode in both specimens cut in RD and LD. The crack growth behavior was affected by the resistance of the hardened area at an early stage of the fatigue process.



(a)

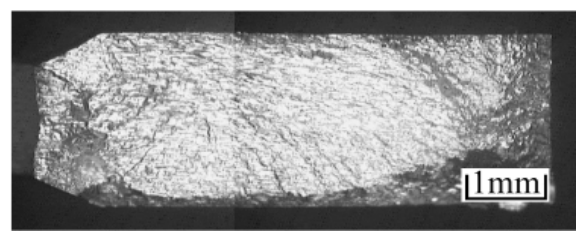

(b)

Fig. 6. Fracture surface where $F_{\mathrm{i}}=14.7 \mathrm{MPa}$ and $S_{a}=100 \mathrm{MPa}$ (a) Cut in RD, (b) Cut in LD.

\section{Conclusions}

The improvement of fatigue life of a holed specimen in A2024-T3 by indentation was examined. The main results obtained are as follow:

(1) In the present experimental conditions, the higher the load applied to the indentation, the longer the fatigue life was obtained.

(2) The crack growth behavior was improved in the vicinity of the indentation region or area.

(3) The hardness distribution and residual stress distribution caused an improvement in the behavior of crack growth.

\section{References}

1. P.F.P.de Matos, A.J. McEvily, P.M.G.P. Moreira, P.M.S.T.de Castro, Int. J. of Fatigue, 29(2007), pp. 575-586.

2. M. Sohel Rana, C. Makabe, G. Fujiwara, Eng. Fail. Anal. 16(2009), pp. 2081-2090.

3. M. Burlat, D. Julien, M. Levesque, T. bui-Quoc, M. Bernard, Engg. Fract. Mech., 75(2008), pp. 2042-2061. 
342 M. S. Ferdous, et al.

4. Shin-Ichi Nishida, Congling Zhou, Nobusuke Hattori, Shengwu Wang, Mat. Sci. \& Eng., A 468-470 (2007), pp. 176-183.

5. Won-Kyun Lim, Jin-Sang Yoo and Seung-Yong Choi; Engg. Fract. Mech.,Vol. 59 (1998), pp. 643-653. 